Reprod. Nutr. Dévelop., 1981, 21 (5B), 783-803.

\title{
Trophicité des muqueuses digestives
}

\author{
par D. BALAS $\left(^{1}\right)$, Françoise SENEGAS-BALAS *, Marie-José BASTIE * \\ Laboratoire d'Histologie Embryologie CHU, Limoges. \\ * U 151 INSERM CHU Rangueil, Chemin du Vallon, Toulouse.
}

\section{Summary. Trophicity of the digestive mucosae.}

The morphological and functional integrity of the digestive mucosae is requisite to the normal progression of the regulated digestive phases during a meal. Therefore, any factor maintaining that integrity over a long period should be considered as having a trophic action on the digestive system.

This paper only discusses long-term trophic regulation in three organs (stomach, pancreas and small intestine) of adult humans and animals.

Some data, especially those concerning the factors playing a role in cell proliferation, are very well documented. The effect of compound endocrine glands (pituitary, adrenals, thyroid) has been known for a long time ; more recently, the gastrointestinal hormones have been implicated but only the long-term actions of gastrin and, to a lesser extent, of cholecystokinin, have been widely studied. The « $G$ » cells and the release of gastrin, independently of secretory action, represent the basic factors controlling the trophicity of the digestive mucosae by stimulating DNA synthesis, undifferentiated cell mulfiplication and the synthesis of RNA, preferentially ribosomal RNA's. The other trophic factors would only act by modulating the permanent release of gastrin. This regulatory scheme (Enoch and Johnson, 1977) permits us to link long-term control, depending on general endocrinology, to immediate control by food intake which also has a basic role in maintaining the trophicity of the digestive mucosae. However, the trophic regulation of digestive mucosae cannot be attributed solely to the pituitary-gastrin system. Several divergent results suggest this. While the pituitary or adrenal functions act on the whole digestive tract, the hyperplasia induced by gastrin is preponderant in the stomach, less in the pancreas and duodenum and practically non-existent in the jejuno-ileum. Also, while hypophysectomy causes symmetrical atrophy of the gastric mucosa by maintaining the parietal cell/peptide cell ratio, gastrin induces elective hyperplasia of the parietal cells. On the contrary, hypophysectomy, adrenalectomy or chemical injections of gastrin cause hypertrophy and hyperplasia of Paneth's cells. Although it is gastrin which primarily affects the cell proliferation of digestive mucosae, other factors also play a role.

The action of the other gastrointestinal hormones, however, is less well known. CCK-PZ has an important trophic role on the exocrine pancreas but the present report shows that it plays a more general part by stimulating the differentiation of all the serous and mucosal cells (pancreatic acinar cells, peptic cells, Paneth's cells, goblet cells and those of Brunner's glands), and thus, by long-term orientation of the digestive mucosae to secretory polarity, Due to its inhibitory action on « $G$ » cells, secretin has an antitrophic action (Wiseman, 1976 ; Johnson, 1978). The effects of somatostatin are more complex and vary with the organ (Lehy, 1979). Our own results on mice are also difficult to inter-

(') Demandes de tirés à part à adresser à : D. Balas, U 151 INSERM, CHU Rangueil, Chemin du Vallon, 31054 Toulouse Cedex, France. 
pret. The action of other hormones (e. q. glucagon, VIP, enteroglucon) has been studied very little or not at all.

Moreover, the trophic action of gastrointestinal hormones is criticizable. Most experiments have more pharmacological than physiological value. In fact, the doses injected are almost always higher (10 to 100 times) than those needed to obtain an immediate effect on the target cell. However, some studies show that the release of endogenous hormone may also have a trophic effect (Willems, 1977). In humans, cimetidin $\left(\mathrm{H}_{2}\right.$ receptor antagonist) has a trophic action on the duodenum, probably resulting from an increase of postprandial gastrinemia.

These studies are centered around the increase of a single hormone, by exogenous supply at repeated, discontinuous massive doses, without any kinematical knowledge of the induced variations of the release or synthesis of other regulatory peptides. Some experiments, however, show that the long-term association of several hormones has different effects : secretin, which normally inhibits the trophic action of gastrin, potentializes caerulein-induced hypertrophy (Petersen, 1979). Our preliminary results, obtained after associating somatostatin $+C C K$ in a chronic injection in the mouse, are described in this paper and confirm the above notion.

The mechanisms of inferregulation and local modulation have only been briefly mentioned. However, they play a major role between two different levels of the digestive system, as well as in the same mucosa. We cite two examples. This paper discusses longterm relations between the exocrine pancreatic function and the mucosa of the small intestine : the pancreatic juice has a trophic action on the upper segments of the small intestine (Balas, 1979) both by its direct action (Alpers, 1975, 1977) and by an indirect hormonal mechanism implicating some gastrointestinal hormones and certainly gastrin (Estival, in press). In mice, gastrin causes an increase in the surface of the jejunal villi and at the same time a reduction in the microvillous surface. The absorbent intestinal surface thus remains constant, probably explaining why hydrolase activities in the brush border do not vary. This process cannot be attributed to a simple deficiency in enterocyte maturation.

Our knowledge of the factors of trophic regulation of the digestive mucosae is thus still rudimentary. The mechanisms are mainly interpreted according to a conventional endocrine scheme, favourizing overall action, depending particularly on hormonal release into the general circulation and admitting a specific secretion for each endocrine cell of the digestive fract. It is likely that recent findings on the endocrine, but also the paracrine and neurocrine (perhaps even exocrine), role of regulatory peptides, as well as the occurrence of many messengers (and their variation in number) in the same cellular entify (Larsson, 1980), should considerably change the schemes actually in use. Classical physiological or histophysiological techniques are probably inadequate for doing research in this field. Methods of cell isolation and cell or organ cultures are becoming necessary. In fact, to obtain a better interpretation of trophic mechanisms, two basic points must be clarified ; we must (i) obtain exact knowledge of the receptor sites of each cell type, and (ii) determine the intracellular processes causing the trophic effect and their relations or divergencies with the mechanisms inducing the immediate hormonal effect.

\section{Introduction.}

Les facteurs de trophicité correspondent classiquement à l'ensemble des mécanismes permettant le maintien de la morphologie et de la fonctionnalité normale d'une muqueuse en dehors de tout épisode de stimulation. Il s'agit donc de processus de régulation à long terme. A ce jour les études ont surtout porté sur la prolifération cellulaire évaluée en terme d'hyperplasie ou d'hypoplasie. Mais cinétiquement un épithélium peut être schématisé et scindé en 4 compartiments intriqués : 
- le compartiment de prolifération, où les cellules souches entrent en mitose et aboutissent au renouvellement cellulaire ;

- le compartiment de différenciation où les clones de cellules immatures vont progressivement acquérir les potentialités des cellules adultes;

- le compartiment fonctionnel. Il correspond à l'ensemble des cellules exprimant, au cours des mécanismes de régulation à courf terme, les caractéristiques et les propriétés physiologiques spécifiques à chaque organe;

- le compartiment de dégénérescence cellulaire où les cellules disparaissent après nécrose, soit par desquamation ef extrusion dans la lumière de l'appareil digestif, soit par phagocytose.

Les conditions morphofonctionnelles basales d'un épithélium digestif seront alors définies par plusieurs paramètres agissant sur ces différents compartiments.

Il n'est pas possible de limiter les facteurs de trophicité aux facteurs d'hyperplasie ou d'hypoplasie mis en évidence par le nombre de cellules, l'index mitotique, la durée du cycle cellulaire des cellules souche, la durée de la phase $S$, la durée de la mitose, le taux d'ADN, etc. II est aussi nécessaire d'y associer sur le plan cytologique tout facteur influençant le temps et la vitesse de passage des cellules dans les compartiments de différenciation et fonctionnels mesurés par les temps de renouvellement celtulaire, ainsi que les facteurs influençant qualitativement la morphologie cellulaire. Ils sont grossièrement appréciés en terme d'hypertrophie ou d'hypotrophie. Sur un plan biochimique ils pourront être évalués par les variations de taux enzymatiques, la modification de la synthèse protéique et des taux d'ARN. Plus que les critères morphologiques les variations des taux enzymatiques et des acides nucléiques au sein d'un tissu permettent, à long terme, d'objectiver des modifications dans l'induction ou la répression génique.

Parmi les facteurs pouvant modifier la trophicité des muqueuses digestives, il faut au moins considérer l'impact de l'endocrinologie générale, les peptides régulateurs locaux (hormones gastro-intestinales) produits par le système endocrinien diffus de l'appareil digestif, des facteurs nerveux, etc... Mais les facteurs exogènes sont également impliqués. Le rôle de l'alimentation est primordial, tant par le stimulus itératif représenté par le repas que probablement par la qualité de l'alimentation; la flore bactérienne intervient également sur le développement et le renouvellement de la muqueuse du tractus digestif.

Nous avons cependant limité cette revue générale à l'étude de certains facteurs trophiques intrinsèques agissant sur l'estomac, le pancréas et l'intestin grêle ef ce uniquement chez l'adulte. Seront donc éliminés les processus de morphogenèse antérieurs au sevrage, les autres organes de l'appareil digestif, ainsi que les facteurs modifiant l'exfoliation cellulaire.

De même nous n'aborderons pas les relations, pourtant très importantes, entre la flore bactérienne et la trophicité des muqueuses digestives ; les rythmes nycthéméraux ne seront qu'évoqués.

Dans un premier temps nous décrirons les notions actuellement bien documentées, nous envisagerons ensuite des données pour lesquelles les travaux sont plus rudimentaires. Enfin nous critiquerons les différentes données de la littérature en tentant de les confronter aux connaissances cyłophysiologiques récentes. 


\section{Ce qui est bien connu.}

De nombreuses éludes ont montré l'influence de l'endocrinologie générale sur la trophicité des muqueuses digestives. Pour la plupart ces travaux sont déjà anciens.

2.1. Hypophyse. - Son rôle a été démontré depuis longtemps (1-2-3-4-5-6). L'hypophysectomie provoque rapidement une atrophie des muqueuses digestives. II s'agit d'une atrophie entraînant une perte de poids et une diminution de volume des organes, avec réduction du nombre des cellules. L'atrophie est globale mais harmonieuse, ne modifiant que peu les répartitions ef les proportions relatives des différents clones cellulaires (fig. 1). Elle est attribuable à une décroissance de la prolifération cellulaire, objectivée par la chute de l'index mitotique et la diminution des taux d'ADN. L'atrophie s'accompagne d'une réduction de la synthèse protéique avec diminution des taux d'ARN, et affaissement de la plupart des activités enzymatiques et sécréłoires. II faut noter que l'hypophysectomie provoque en outre une chute de la gastrinémie et de la gastrine antrale (6-7).

Parmi les hormones hypophysaires, l'hormone de croissance semble avoir un rôle primordial (6-8-9-10-11) : elle restaure, après hypophysectomie, la plupart des paramètres morphologiques et fonctionnels. En particulier elle normalise la gastrine antrale ef sérique.

L'ACTH est la deuxième hormone concernée, elle augmente la libération de gastrine, son action est surtout nefte chez l'animal hypophysectomisé et/ou surrénalectomisé montrant ainsi que l'effet de l'ACTH sur la cellule G, productrice de gastrine, est direct et non uniquement relayé par les glucocorticoïdes (12). Le rôle direct de l'ACTH a également été envisagé sur les niveaux enzymatiques du pancréas où son action par blocage de la transmission ganglionnaire a été suspectée (13).

D'autres sécrétions hypophysaires sont probablement impliquées. En effet au cours des épisodes de gestation et de lactation, une hyperplasie de la muqueuse fundique et du pancréas a été observée (14).

La prolactine joue sûrement un rôle (6-15) expliquant peut-être l'augmentation des cas de pancréatite au cours de la grossesse dans l'espèce humaine (16) mais les facteurs hormonaux libérés par le placenta sont sûrement plus importants (14).

2.2. Glandes surrénales. - Chez l'adulte le rôle joué par les glandes surrénales (10-17-18-19-20) est moins fondamental que celui de l'hypophyse, alors que pendant la période néonatale et au cours du sevrage, l'influence des surrénales est prépondérante. Ces notions dépassent le cadre fixé à cette revue (cf. éventuellement réf. 21). Le rôle des glandes surrénales sur les phénomènes de prolifération cellulaire est discutable.

Les discordances observées sont probablement attribuables à des différences dans l'équilibration saline de la boisson au cours de l'expérimentation (22).

Par contre la surrénalectomie entraine une diminution des taux d'ARN et corrélativement une chute des niveaux enzymatiques et des paramètres sécrétoires aussi bien au niveau de l'estomac que du pancréas ou de l'intestin grêle.

Comme après hypophysectomie, le nombre des cellules $G$ et les taux de gastrine antrale diminuent sans que toutefois la gastrinémie soit affectée (23). 
Les glucocorticoïdes restaurent les déficits observés après surrénalectomie. Cette restauration correspond à l'action générale positive et bien connue des glucocorticoïdes sur les étapes antérieures à la traduction, dans les mécanismes de contrôle ef d'induction de la synthèse protéique.

L'influence des glucocorticoïdes se traduit plus spécifiquement au niveau du tube digestif par une augmentation de la gastrine antrale accompagnée d'une augmentation du nombre de cellules $G$ mais également de la gastrinémie basale ef post-prandiale (23).

Les glucocorticoïdes ne seraient pas les seuls stéroïdes ayant un effet trophique. Il esí possible que les minéralocorticoïdes aient aussi un rôle facilitateur et augmenleril ies iaux d'ARN (24).

Enfin, bien que peu étudiés et correspondant à des travaux très anciens, la médullo-surrénale et les adrénergiques pourraient exercer une fonction freinatrice sur la prolifération cellulaire (20).

2.3. Thyroïde. - Les études sont peu nombreuses (8-25) mais confirment son action générale anabolisante ; les hormones thyroïdiennes augmentent le faux d'ARN et facilifent la synthèse protéique. Cependant l'intégrité de la thyroïde ne semble pas primordiale. Les hormones thyroïdiennes joueraient surtout un rôle permissif en potentialisant les effets de l'hormone de croissance (26). Sur le plan pathologique il faut noter que les hyperthyroïdies s'accompagnent d'une hypergastrinémie (27).

2.4. Autres glandes endocrines. - Les autres glandes endocrines ont été peu étudiées. Le rôle de la fonction testiculaire a cependant été envisagé (25-28).

Il faut noter que l'ensemble des travaux portant sur les relations à long terme entre l'hormonologie générale et l'appareil digestif montrent systématiquement des variations du taux de gastrine. Cette concordance évoque une éventuelle convergence des effets trophiques qui pourraient être alors relayés par l'action locale de la gastrine sécrétée, principalement au niveau de l'antre gastrique, par les cellules « $G$ ». Les travaux de l'équipe de Johnson (6) ont bien mis en évidence le rôle fondamental de la gastrine dans le maintien de la trophicité des muqueuses digestives.

2.5. Rôle trophique de la gastrine. - La gastrine apparaît, au niveau actuel de nos connaissances, l'hormone trophique principale des muqueuses digestives (6). En effet elle provoque une augmentation du DNA dans le fundus, le pancréas et l'intestin grêle principalement dans la zone duodénale (29-30-31-32-33-34-35-36-37-38-39). Elle entraîne en outre une élévation des taux d'ARN, des protéines tissulaires ef de certains paramètres sécrétoires; au niveau de l'estomac la sécrétion acide maximale stimulée est considérablement accrue ; au niveau du pancréas, les concentrations en amylase et chymotrypsine sont augmentées pour certains (40), et non modifiées pour d'autres auteurs (41).

La cinétique des effets de la gastrine sur les mécanismes de synthèse des acides nucléiques est bien connue (37). Une à deux heures après injection de pentagastrine, une augmentation transitoire des ARNm est observée. Mais c'est surtout un accroissement très important des $A R N r$ et $A R N t$ vers la $6^{\circ}$ heure, significatif jusqu'à la $12^{e}$ heure, qui représente l'action majeure de la gastrine sur une des étapes de la transcription. L'augmentation des taux d'ARN est accompagnée d'une forte stimulation de la syn- 


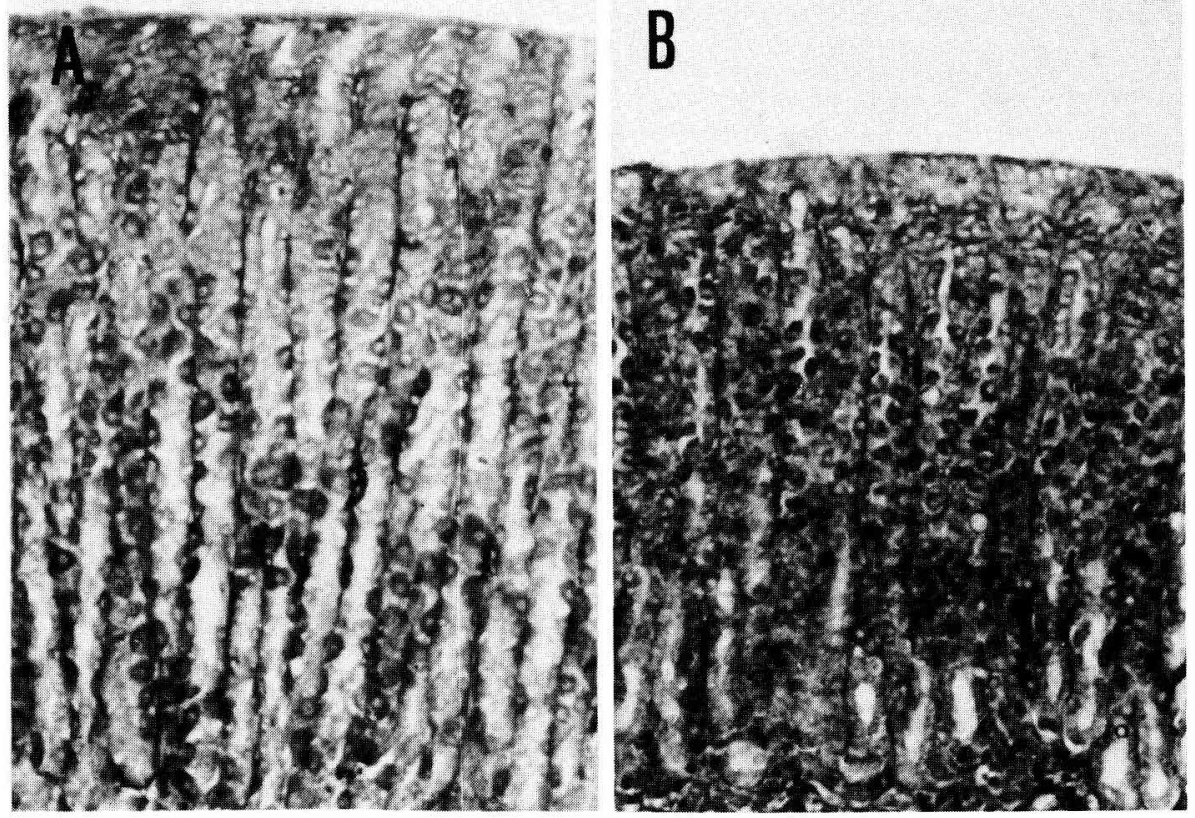

Fig : 1

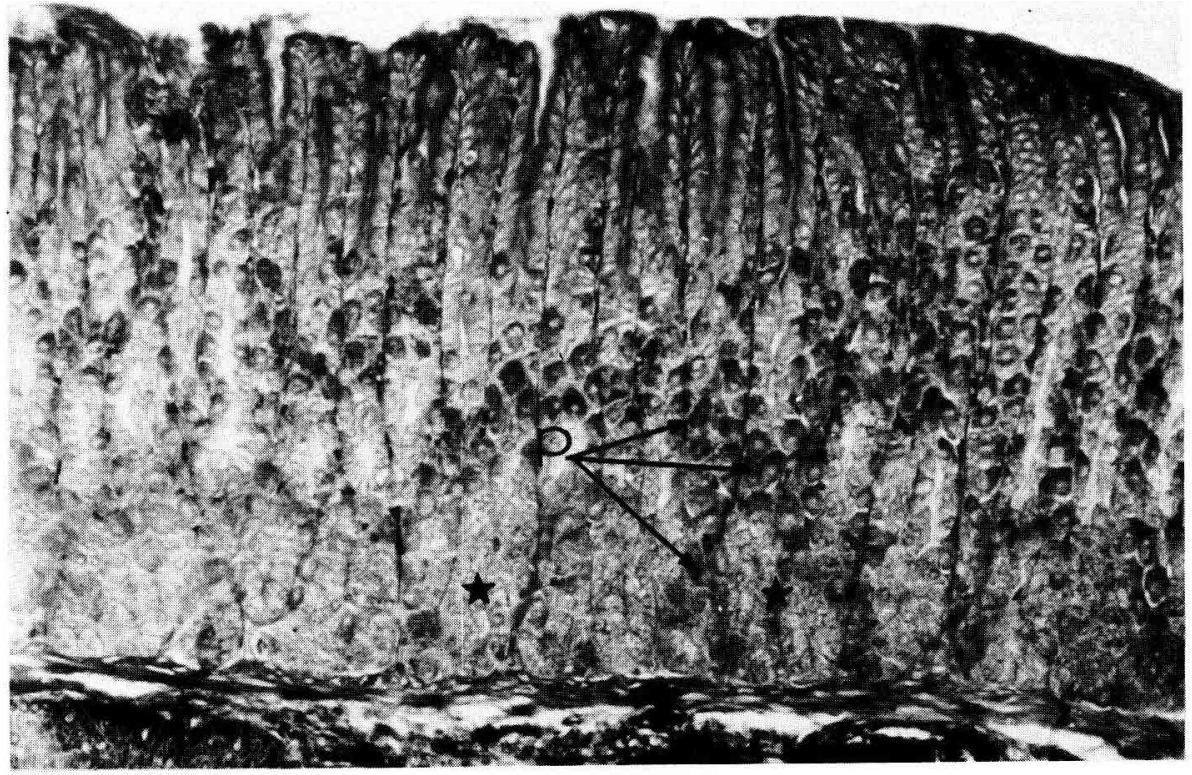

Fig : 3 
thèse protéique. Enfin $16 \mathrm{~h}$ après l'injection de gastrine, la duplication de l'ADN est induite au cours de la phase $S$ du cycle cellulaire provoquant ultérieurement une élévation de l'index mitotique.

L'action trophique de la gastrine est donc remarquable : l'hormone induit la prolifération cellulaire ; elle est hyperplasiante. Elle induit également la stimulation de la synthèse protéique; elle est hypertrophiante. L'analyse cytologique montre cependant que l'action trophique de la gastrine ne s'exerce pas sur l'ensemble des différents types cellulaires d'un même organe. En effet sur le fundus la gastrine entraîne l'hyperplasie et l'hypertrophie des cellules pariétales et des cellules indifférenciées (42-43-44) mais n'affecte que peu les cellules principales. Elle ne provoque pas de modification au niveau de l'antre gastrique (38). Il est vrai qu'il s'agit de la zone élective de synthèse-sécrétion de l'hormone.

2.6. Un schéma de régulation trophique. - Enochs et Johnson (6) devant l'action trophique spécifique de la gastrine, devant l'action élective de l'ensemble des principales glandes endocrines sur le taux de gastrine, ont alors établi un schéma global de régulation de la trophicité des muqueuses digestives (fig. 2). Pour ces auteurs la

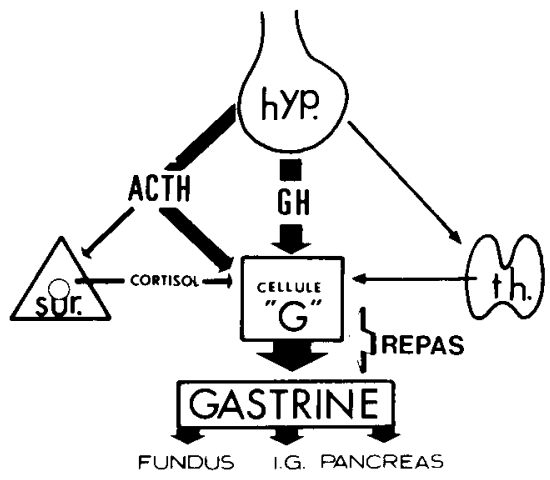

FIG. 2. - Schéma de régulation trophique (d'après Enochs et Johnson, 1977). (Hyp : hypophyse, Sur : glandes surrénales, Th: glande thyroïde, IG : intestin grêle).

gastrine représente l'hormone clef, les autres facteurs trophiques endocriniens généraux étant obligatoirement relayés par la libération accrue de la gastrine ef par son action locale.

Ce schéma synthétique est séduisant et représente encore actuellement la base unanimement reconnue de la régulation trophique et à long terme de l'appareil digestif.

FIG. 1. - Les photographies au même grandissement $(\times 100)$ montrent nettement les différences morphologiques entre un rat témoin (A) et hypophysectomisé depuis 15 jours (B), au niveau de la muqueuse fundique. L'atrophie est nette, les cellules sont de plus petite taille mais leur répartition n'esi pas modifiée.

FIG. 3. - Aspect morphologique de la muqueuse fundique chez la Souris après injections chroniques de $C C K-P Z$ (37, 5 U. 3 fois par jour pendant 12 jours). Noter l'hypertrophie et l'hyperplasie des cellules principales au fond des glandes $\left(^{*}\right)$ ef la raréfaction relative des cellules pariétales $(\mathrm{P})$ dans cette zone (grossièrement : $\times 100$ ). 


\section{Ce qui est moins bien connu.}

Si le schéma de régulation trophique établi par Enochs et Johnson (6) représente une base d'étude, de nombreux autres facteurs doivent participer aux mécanismes de régulation à long terme de la fonctionnalité basale de l'appareil digestif. Ils ont cependant été beaucoup moins étudiés.

3.1. Les autres hormones gastro-intestinales.

Parmi les autres hormones gastro-intestinales, les effets à long terme de la CCKPZ sont les mieux connus.

3.1.1. CCK-PZ. - L'action trophique de la CCK-PZ semble plus spécifique et s'exerce principalement sur son organe cible dans le schéma de régulation à courf terme, le pancréas exocrine. Elle provoque en effet sur cet organe une augmentation très significative à la fois des taux d'ADN et d'ARN (35-45-46-47-48). Des doses plus importantes entraînent également des phénomènes hypertrophiques sur le duodénum et le fundus (49). L'hyperplasie et l'hypertrophie des acini pancréatiques sont suivies d'une augmentation significative des taux d'amylase, de chymotrypsine et de trypsine (4146-47-48-50-51), d'une élévation discutable de l'activité lipasique (50).

Nos propres expérimentations (52 et publication en cours) comparant les résultats biochimiques et histologiques après injection chronique de CCK-PZ chez la souris, nous laissent supposer que l'action de l'hormone est plus étendue.

En outre nous avons pu observer, à côté des effets très spécifiques, sur le pancréas, une hypertrophie et une hyperplasie des cellules peptiques (fig. 3) (confirmées par l'élévation de l'activité peptique), des cellules de Paneth (confirmées par l'élévation de l'activité lyłique intestinale). La CCK-PZ induit également une hypertrophie et une hyperplasie des cellules muqueuses qu'il s'agisse de la glande de Brünner duodénale, des cellules caliciformes, ou à un moindre degré des cellules mucipares de l'épithélium cryptique du revêtement superficiel gastrique. De ce fait nous envisagerions un rôle plus spécifique dévolu à la CCK-PZ. Si la gastrine stimule globalement la prolifération des cellules souches, la CCK-PZ pourrait exercer son action sur une étape ultérieure en induisant et/ou en accélérant la différenciation des cellules à polarité sécrétoire des muqueuses digestives.

3.1.2. Sécrétine. - Son action s'oppose à celle de la gastrine.

La sécrétine pourrait donc être considérée comme une hormone antitrophique (53). Cet effet semble cependant indirect et la conséquence d'une inhibition de la libération de gastrine (54).

Pour d'autres auteurs la sécrétine exercerait une action hypertrophiante sur le pancréas (48).

\subsubsection{Somatostatine. - Peu de travaux sur ce peptide ont été réalisés à ce jour.}

Lehy, Dubrasquet et Bonfils (55) ont pu montrer que la somatostatine inhiberait la prolifération mitotique fundique ef antrale et s'opposerait en partie aux effets gastriniques. Sur l'intestin grêle, il faut cependant noter que certains résultats paraissent d'interprétation difficile, mais évoquent l'influence des rythmes nycthéméraux.

Nos expérimentations personnelles sur la Souris nous permettent de mettre en évidence les résultats préliminaires suivants (52 et publication en cours) : la somatos- 
tatine provoque une diminution du nombre de cellules pariétales, sans modification de leur diamètre. Elle entraîne également une hypotrophie des acini pancréatiques avec diminution corrélative des activités chymotrypsiques ef lipasiques, sans variation nolable des taux amylasiques. Ces modifications semblent en rapport avec l'action inhibitrice de l'hormone à court terme. Nous observons cependant d'autres modifications dont certaines sont paradoxales : une augmentation du nombre et de la charge granulaire des cellules de Paneth associée à l'élévation des taux de lysozyme, ainsi qu'une hyperplasie ef une hypertrophie modérées des cellules peptiques associées à l'accroissement de l'activité peptique.

3.1.4. Autres peptides régulateurs. - L'éventuelle action trophique des autres hormones digestives n'a donné lieu qu'à quelques travaux ne permettant pas de porter des conclusions définitives.

Le glucagon, malgré son action inhibitrice sur la sécrétion acide de l'estomac, possède une action trophique sur le fundus, similaire à celle de la gastrine mais netfement moins importante (environ 40 p. 100 des effets de la pentagastrine à des doses équimoléculaires) (36). Sur des bases anatomocliniques l'entéroglucagon a été soupçonné d'avoir un effeł trophique sur l'iléon humain (56).

Enfin le VIP n'aurait aucune action trophique sur le fundus ou le côlon (36). II pourrait cependant posséder une action similaire à la sécrétine. Il n'existe pas de travaux permettant d'envisager une participation à la trophicité du tube digestif des autres hormones gastro-intestinales, ni des autres modulateurs locaux dont le nombre cependant s'avère de plus en plus considérable (57).

\subsection{Les mécanismes d'interrégulation.}

A côté des systèmes de régulation que nous venons d'évoquer (endocrinologie générale et peptides régulateurs locaux), des mécanismes plus spécifiques peuvent intervenir et se traduire par des phénomènes adaptatifs entre deux étages éloignés d'un même organe, ou même entre deux organes distincts de l'appareil digestif.

Les mécanismes compensatoires, d'hypertrophie et d'hyperplasie, d'un segment de l'intestin grêle après résection massive jéjuno-iléale sont bien connus (58-59). Le processus réactionnel semble en grande partie dépendre d'une augmentation de la gastrinémie (59) sans toutefois qu'il soił réellement possible d'en préciser le mécanisme qui est cependant indirect.

Les interrelations à long terme entre l'estomac ef le pancréas ou l'intestin grêle sont mal connues. Nous avons par contre montré (60-61) qu'il existait des relations étroites entre la fonction pancréatique exocrine (et le suc pancréatique déversé dans la lumière intestinale), la morphologie et les niveaux enzymatiques de la muqueuse intestinale. Après ligature des canaux pancréatiques chez l'animal, des phénomènes d'atrophie partielle villositaire apparaissent accompagnés d'une hypertrophie ef hyperplasie des cellules de Paneth, des cellules muqueuses caliciformes. Certaines activités enzymatiques de la bordure en brosse sont également augmentées ainsi que l'activité lytique. La fonction pancréatique exocrine joue donc un rôle sur les mécanismes de différenciation de la muqueuse intestinale et plus particulièrement sur la polarité sélective de différenciation entre les entérocytes et les cellules sécrétrices, les deux groupes cellulaires dérivant cependant de la même cellule souche (62).

Ce mécanisme d'interrégulation peut êfre soit direct, en accord avec l'action 
désorbante du suc pancréatique sur la bordure en brosse des entérocytes (63-64), soit indirect par un mécanisme humoral plus complexe. L'observation d'une augmentation spécifique de la phosphatase alcaline, de l'aminopeptidase et de l'activité sucrasique uniquement dans le duodénum, donc dans une zone sus-jacente au déversement du suc pancréatique, privilégie cette deuxième hypothèse (61) et est probablement à rapprocher des résultats récents montrant des variations des taux sériques de certaines hormones gastro-intestinales, soit après dérivation de la sécrétion pancréatique chez le Porc (65), soit après utilisation d'enzymes pancréatiques ou de leurs inhibiteurs ajoutés à long terme dans l'eau de boisson chez le Rat (66).

3.3. Facteurs intra-épithéliaux, participant à la régulation des mécanismes de différenciation et prolifération cellulaire.

Ils sont encore moins bien connus pour les épithéliums digestifs. Nous citerons cependant les travaux de Sassier et Bergeron (67) qui ont mis en évidence l'existence de facteurs d'inhibition de la prolifération cellulaire, probablement apparentés aux chalones, dont les rôles sont mieux connus sur la peau et les différenciations ectodermiques (84). Les facteurs intra-épithéliaux mériteraient pourtant d'être envisagés. Une expérimentation récente, étudiant morphométriquement les effets chroniques de la gastrine sur l'épithélium jéjunal ou iléal, nous a montré des résultałs surprenants : si l'hormone provoque une augmentation de l'aire villositaire à l'étage jéjunal chez la Souris, elle entraine parallèlement une diminution significative de l'aire microvillositaire de la bordure en brosse entérocytaire en réduisant la hauteur des microvillosités. De ce fait l'aire absorbante totale jéjunale n'est pas modifiée par la gastrine, ni par aucune des autres hormones festées (52). Il est d'ailleurs remarquable de consfater que le niveau des enzymes de la bordure en brosse ne varie pas, expliquant ainsi que les dissociations entre l'aire villositaire et le taux des hydrolases de la bordure en brosse (61-68), parfois observées, ne sont peut-être qu'apparentes. Ces résultats suggèrent en outre l'existence d'un système d'interrégulation locale entre les phénomènes de prolifération, jouant sur la hauteur ef le nombre de villosités intestinales, et le niveau fonctionnel de la bordure en brosse. Nous ne pouvons cependant en préciser pour le moment le mécanisme.

\subsection{Les facteurs exogènes.}

$\mathrm{Si}$ les facteurs endogènes, plus particulièrement humoraux, sont probablement fondamentaux dans le contrôle de la trophicité des muqueuses digestives, de nombreux facteurs exogènes peuvent également intervenir.

3.4.1. Le repas. - Il est important de souligner que les épisodes de réalimentation successifs dans le nycthémère représentent le stimulus primordial de trophicifé. En effet le jeûne prolongé chez l'animal (69-70-71-72), les états cachectiques ou l'alimentation parentérale (73) provoquent une importante atrophie des muqueuses digestives avec affaissement des paramètres enzymatiques, de la gastrine sérique et antrale. Les mécanismes de régulation à long terme, contrôlant la trophicité, et les mécanismes de régulation à court terme, contrôlant la digestion, sont donc intimement liés. Le schéma établi par Enochs et Johnson (6) (fig. 2) a le mérite de montrer que la gastrine peut représenter le dénominateur commun aux deux types de régulation à court et long terme. Mais il est évident que les variations des taux des autres peptides régulateurs après stimulation par le repas, participent également à long terme à la régulation 
trophique. Il est de toute façon addmis que la réalimentation est nécessaire pour maintenir le taux basal intra-épithélial des hormones gastro-intestinales, et en tout cas celui de la gastrine (72).

3.4.2. Facteurs qualitatifs et sélectifs apportés par l'alimentation. - Certains facteurs provoqueraient plus spécifiquement la libération des hormones gastrointestinales, les peptones celui de la gastrine, les peptones et les graisses celui de la CCK-PZ et du $\mathrm{GIP}$, la diminution de $\mathrm{pH}$ celui de la sécrétine, etc... L'équilibre de la ration alimentaire peut donc intervenir sur les taux relatifs des différents peptides régulateurs. Mais la nature même des aliments, ou celle d'ingesta ne possédant pas de valeur alimentaire propre (additifs, médicaments, fraction non digestible des aliments, etc...) doivent intervenir sur les mécanismes internes de trophicité.

Nous avons choisi pour exemple la pénicillamine dont nous avons pu démontrer la toxicité chez le Rat (74). Cette molécule, chélatrice des métaux lourds, est utilisée en thérapeutique au cours des intoxications par les sels de plomb ou de mercure, la maladie de Wilson, et cerłaines maladies rhumatismales. A forte dose, la pénicillamine provoque, en association avec un régime hyperlipidique carencé en cuivre, une dégénérescence totale des acini pancréatiques sans atteinte notable des structures canalaires et du pancréas endocrine (75). Nous avons nous-même constafé (74), que la pénicillamine provoquait également une atrophie très importante de la zone basse de l'intestin grêle, corrélative à la forte diminution du nombre des mitoses, associée à une hyperplasie des cellules caliciformes et à une transformation muqueuse des cellules de Paneth. Si divers mécanismes, directs ou indirects, peuvent être invoqués il nous semble important de signaler la possibilité d'une interaction directe éventuelle entre la pénicillamine ef certaines hormones digestives. La pénicillamine peut se lier avec l'ocytocine par addition nucléophile, provoquant ainsi une rigidification de l'hormone et une incapacité pour celle-ci de reconnaître les sites récepteurs spécifiques (76-77). Un mécanisme similaire nous semble possible avec les peptides régulateurs infestinaux. En effet des études en chromatographie haute performance nous ont montré que l'interaction entre la pénicillamine ef certaines hormones digestives étaient fortes pour le VIP, la somatostatine, et la CCK-PZ, pratiquement nulle avec la gastrine ou la sécrétine. II faut alors remarquer que la concentration en VIP est maximale dans l'iléon (78) et le côlon, zone où les phénomènes atrophiques sont les plus importants après pénicillamine. De même la CCK-PZ (52-79-80) et la somatostatine agissent spécifiquement sur la cellule de Paneth. Or la polarité de différenciation sécrétoire de cette cellule est fotalement perturbée après pénicillamine. Enfin l'atteinte sélective des acini pancréatiques, sans modification de la composante canalaire, ainsi que l'absence de modifications morphologiques de l'épithélium gastrique et duodénal, peuvent être en relation étroite avec les différences d'interaction observées entre pénicillamine et certaines hormones gastro-intestinales (gastrine, CCK-PZ, sécrétine) s'il est tenu compte de leur zone d'action élective à long terme.

Bien qu'éloigné des conditions nutritionnelles normales, cet exemple montre que des facteurs exogènes peuvent venir inferférer sur les mécanismes intrinsèques de régulation trophique. Il faut s'attendre à ce que d'autres facteurs apportés par l'alimentation ou par la prolifération de la flore bactérienne, jouent un rôle similaire. lis sont à rapprocher du concept de "cross-linking » (81), dont le développement 
actuel devrait apporter de nombreux renseignements et peut-être permettre de mieux comprendre certains mécanismes adaptatifs.

\subsection{Autres facteurs pouvant agir sur la trophicité.}

Il peut paraître surprenant de ne pas avoir envisagé le rôle éventuel du système nerveux. L'influence du tonus vagal semble cependant moins importante que celle d'autres paramètres préalablement cités. La vagotomie, chez l'animal comme chez l'homme, n'entraîne pas de signes majeurs d'atrophie (82-83). La vagotomie diminuerait cependant le nombre des cellules principales fundiques ; elle réduit la différenciation en cellules pariétales (84) mais surtout elle provoque une augmentation de la gastrinémie basale et post-prandiale (85-86). Le rôle principal du vague pourrait donc être un contrôle permanent de la prolifération (en l'inhibant) des cellules à gastrine (87).

Sans que l'on puisse parler d'un mécanisme de régulation, il est probable que les phénomènes de prolifération des muqueuses digestives soient partiellement soumis à des rythmes circadiens. Les variations observées sont cependant contradictoires car les épisodes de réalimentation interfèrent (84).

Enfin il est bien évident que tous les facteurs qui modifient, en plus ou en moins, l'importance de l'exfoliation des muqueuses digestives, participent à l'équilibre trophique. Comme nous l'avions signalé dans l'introduction, nous ne les aborderons pas dans cette revue.

\section{Critiques et conclusions.}

Les facteurs pouvant intervenir dans les mécanismes de régulation trophique sont donc multiples, qu'ils soient endogènes ou exogènes. Si le schéma proposé par Jonhson peut représenter un modèle simple et encore facilement interprétable, il serait actuellement nécessaire d'y adjoindre de très nombreux paramètres supplémentaires rendant finalement impossible une compréhension synthétique de l'ensemble des phénomènes observés. Par ailleurs ce schéma est par lui-même critiquable. En effet, à travers ce schéma il faudrait s'attendre à ce que les effets de l'hypophysectomie ou de la surrénalectomie s'opposent en grande partie à ceux d'un apport de gastrine exogène.

Ce n'est pas systématiquement le cas.

Nous citerons trois exemples :

- sil'hypophysectomie provoque une atrophie globale de la muqueuse fundique avec conservation du rapport : cellules principales/cellules pariétales, les injections de gastrine entraînent une diminution de ce rapport en privilégiant la prolifération ef la différenciation des cellules à $\mathrm{HCl}(44)$;

- I'hypophysectomie et la surrénalectomie (18-19) provoquent une hyperplasie des cellules de Paneth. La gastrine entraîne également l'hyperplasie et l'hypertrophie de ce type cellulaire (52) ;

- l'action trophique hypophysaire s'exerce à un même degré sur les différents étages de l'intestin grêle. Ainsi l'index mitotique est significativement diminué, et dans les mêmes proportions, au niveau de la zone haute du jéjunum ou dans l'iléon. Au contraire après injection chronique de gastrine (52) l'index mitotique et l'aire villo- 
sitaire intestinale sont significativement plus augmentés dans les zones duodénojéjunales.

Les études envisageant l'action à long terme des hormones gastrointestinales, après apport exogène du peptide chez l'animal, sont également discutables. En effet, les doses utilisées dans les expérimentations sont presque toujours nettement supérieures à celles nécessaires ( $\times 10$ à $\times 100$ fois) pour éliciter l'effet sécrétoire maximal sur les cellules cibles spécifiques de l'hormone. Ces différentes expérimentations sont donc plus pharmacologiques que réellement physiologiques. Toutefois certains travaux montrent que l'augmentation de la gastrinémie endogène, par transposition colique de l'antre par exemple (88), est suivie de phénomènes d'hyperplasie et d'hypertrophie fundiques (89). De même l'action trophique (52- publication en cours) ef protectrice (90) d'un anti-récepteur $\mathrm{H}_{2}$, tel que la cimétidine, pourrait éventuellement être attribuée à l'augmentation importante de la gastrinémie post-prandiale (91-9293-94). Par ailleurs, au cours des différentes expérimentations animales, les hormones ont été administrées massivement à doses itératives, donc en provoquant des pics de concentration et ainsi des variations obligatoires mais non mesurées des autres hormones. De ce fait, il devient difficile d'attribuer l'action trophique observée à un effet direct de l'hormone injectée. Les perturbations induites dans l'équilibre des peptides régulateurs ou d'autres facteurs d'homéostasie devraient être pris en considération. En outre, des expériences d'associations hormonales montrent que les résultats observés ne correspondent pas à l'effet additif ou de potentialisation de deux hormones considérées isolément. Ainsi, la sécrétine, antitrophique lorsqu'elle est injectée seule, possède une action potentialisatrice sur l'hypertrophie pancréatique induite par la caeruléine (homologue de la CCK-PZ) mais ne modifie pas l'action hyperplasiante de cette dernière (48-95).

Nos résultats préliminaires, testant chez la Souris l'association à doses équimoléculaires de la CCK-PZ et de la somatostatine, montrent également des résultats contradictoires aussi bien sur le plan morphologique que par l'étude des niveaux enzymatiques. Si la CCK est sans effet, et si la somatostatine (52) provoque une diminution significative du nombre des cellules pariétales, paradoxalement l'association CCK $+S$ entraîne une augmentation fortement significative du nombre de ces cellules (52, publication en cours). II n'y a pas d'effet additif sur l'élévation du nombre de cellules principales. Les résultats sont également dissociés et différents suivant les enzymes pancréatiques considérées, amylase, chymotrypsine ou lipase (fig. 4). En outre, en
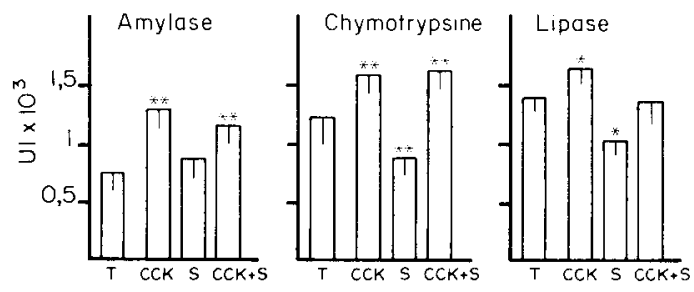

FIG. 4. - Variations différentielles des niveaux enzymatiques du pancréas (exprimées en unités par gramme) après imprégnation chronique chez la Souris par la CCK-PZ (37,5 unités $/ \mathrm{kg}$ de CCK-GIH 3 fois par jour pendant 12 jours), par la somatostatine (S) $(8 \mu \mathrm{g} / \mathrm{kg}$ de somatostatine Serono 3 fois par jour pendant 12 jours) et l'association $C C K+S$ aux mêmes doses pendant 12 jours. $T=$ groupe d'animaux témoins n'ayant reçu que du sérum physiologique. 
microscopie électronique, le pancréas exocrine est fortement modifié avec apparition de fusions séquentielles des grains de zymogène dont certains sont plus clairs aux électrons et acquièrent parfois un aspect en cocarde ; les images de crinophagie sont nettement plus nombreuses. Les aspects ultrastructuraux sont très proches de ceux observés dans les pancréatites induites chimiquement.

Il semble donc difficile d'analyser les facteurs de trophicité en termes de cytophysiologie traditionnelle. Les résultats que nous avons obtenus après gastrine sur les variations morphologiques de l'intestin grêle, ou les expériences d'association $S+C C K-P Z$, suggèrent fortement l'existence de mécanismes de modulation locale qui doivent être rapprochés des connaissances récentes sur les peptides régulateurs.

Ces notions révèlent alors des insuffisances dans les différentes expérimentations réalisées el leur interprétation.

Associée au mode de sécrétion de type endocrine, le système endocrinien diffus possède d'autres modes sécrétoires qui doivent être pris en considération. Il faut plus particulièrement citer les mécanismes paracrines (96) qui créent une imprégnation hormonale locale que ne peut en aucun cas refléter le taux sanguin circulant. Il faut en outre décrire la présence intraépithéliale de couples de cellules endocrines adjacentes évoquant la possibilité de circuits courts de régulation (57-97). Après les travaux de Uvnas-Wallensten (98), des taux importants de peptides régulateurs ont été retrouvés dans les lumières ef les sécrétions digestives (99). Il ne semble pas exclu que leur présence puisse induire des effets immédiats ou à long terme sur les étages sous-jacents du tube digestif.

Le concept classique admettant une sécrétion hormonale spécifique pour un type cellulaire donné doit également être discuté. De nombreux exemples de cellules endocrines polysécrétoires sont actuellement décrits (100-101). L'exemple le plus marquant est justement représenté par les cellules « $G$ » dont le polymorphisme granulaire est peut-être en relation avec la pluralité des formes de gastrine (102) mais également avec la présence de composants immunologiquement apparentés à l'hormone de croissance mais surfout à l'ACTH (103-104). Bien que cette notion ait été récemment critiquée par d'autres auteurs (105-106), il est encore plus surprenant de constater que les taux de gastrine et ceux de la composante «ACTH like » puissent inversement varier en fonction de l'état de jeûne ou de réalimentation de l'animal (104). Il faut également noter que de nombreux peptides régulateurs sont à la fois présents dans le névraxe et le tube digestif (CCK, VIP, gastrine, somatostatine, substance P...). La gastrine, au niveau central, a récemment été suspectée de provoquer l'inhibition de la sécrétion de corticostérone probablement par blocage du « releasing factor» induisant la sécrétion d'ACTH (107). Enfin des peptides régulateurs comme le VIP, la somatostatine, les variantes de faible poids moléculaire de la CCK-PZ sont retrouvés non seulement au niveau des cellules endocrines mais également dans certaines terminaisons nerveuses et synapses ganglionnaires périphériques de l'appareil digestif (101). L'existence des neurones peptidergiques laisse alors entrevoir la possibilité d'une régulation locale plus fine et devrait surtout permettre de relier les concepts hormonaux et nerveux qui s'opposent souvent en physiologie conventionnelle. Les mécanismes de trophicité dépendent non seulement des différents groupes hormonaux mais également de leurs variants moléculaires. Il est sûrement justifié de vérifier si les différences d'efficacité observées dans des expériences de stimulation à court 
terme (108-109-110) ne se retrouvent pas également dans les phénomènes de régulation à long terme. D'autre part, une exacte compréhension des mécanismes de régulation trophique nécessiterait une connaissance précise des sites récepleurs spécifiques à chaque type cellulaire ; compte tenu des mécanismes de prolifération et différenciation des clones cellulaires, il semble évident que leur connaissance détaillée ef plus particulièrement chronologique devient impérative.

Enfin les mécanismes inira-cellulaires régulant les processus de prolifération et différenciation cellulaires des épithéliums digestifs par l'intermédiaire des peptides régulateurs n'ont été que peu étudiés. Seuls quelques travaux ont porté sur l'action intra-cellulaire de la gastrine (110-111) mais ils n'apportent pas de précisions exactes sur d'éventuelles étapes où la gastrine peut intervenir dans l'ensemble des phénomènes qui précèdent la traduction ribosomale. Il faut d'ailleurs noter que les mécanismes de régulation à long terme sont sûrement différents de ceux, mieux connus, contrôlant à court terme les processus de synthèse-sécrétion cellulaire. Le schéma actuellement admis du « stimulus-coupling » (112) de la cellule acineuse pancréatique en fournit une illustration. En effet dans ce schéma la stimulation par les cholinergiques ou par la CCK-PZ, aboutit, à partir des récepteurs spécifiques, à une chaîne convergente où la mobilisation du calcium intra-cellulaire suivie par la production de GMPc représentent les facteurs primordiaux déclenchant la sécrétion enzymatique. A travers ce processus de régulation, s'il était univoque, il faudrait admettre que les substances cholinergiques, au même titre que la CCK-PZ, puissent induire à long terme des phénomènes d'hyperplasie et d'hypertrophie des cellules acineuses pancréatiques. Or il est bien démontré que les substances cholinergiques n'ont aucune action hyperplasiante sur le pancréas exocrine (113). D'autres voies de régulation intra-cellulaires doivent donc être envisagées et restent à découvrir. Il est pourtant évident que certains peptides régulateurs, directement ou indirectement, ont une action au niveau même du noyau cellulaire (comme le montre clairement la figure 5 et les variations nucléaires observées).

Si de très nombreux auteurs ont étudié la trophicité des muqueuses digestives, les différents travaux ne permettent pas encore d'appréhender avec précision les mécanismes intrinsèques de régulation. Seules des recherches utilisant des modèles in vitro, isolement cellulaire, culture cellulaire, pourront, confrontées aux résultats observés sur l'animal entier, parfaire notre connaissance. Il est cependant certain qu'aux notions cytophysiologiques classiques se substituent progressivement des concepts de modulation où les facteurs périphériques, exogènes ou endogènes, ne représentent probablement que des éléments " gachettes » induisant ou initiant un processus de régulation locale ou loco-régionale.

Journées Digestion-Absorption de l'Association française de Nutrition, Toulouse-Auzeville, 20-21 novembre 1980.

Remerciements. - La plupart des travaux expérimentaux personnels présentés ou cités dans cette revue ont été réalisés à l'Unité $U 151$ du Professeur A. Ribet. Nous tenons à le remercier pour certaines critiques et corrections apportées. Nous tenons également à remercier vivement E. Cremer pour son aide dans les recherches bibliographiques, L. Pradayrol pour l'exécution et l'interprétation de certains dosages, 

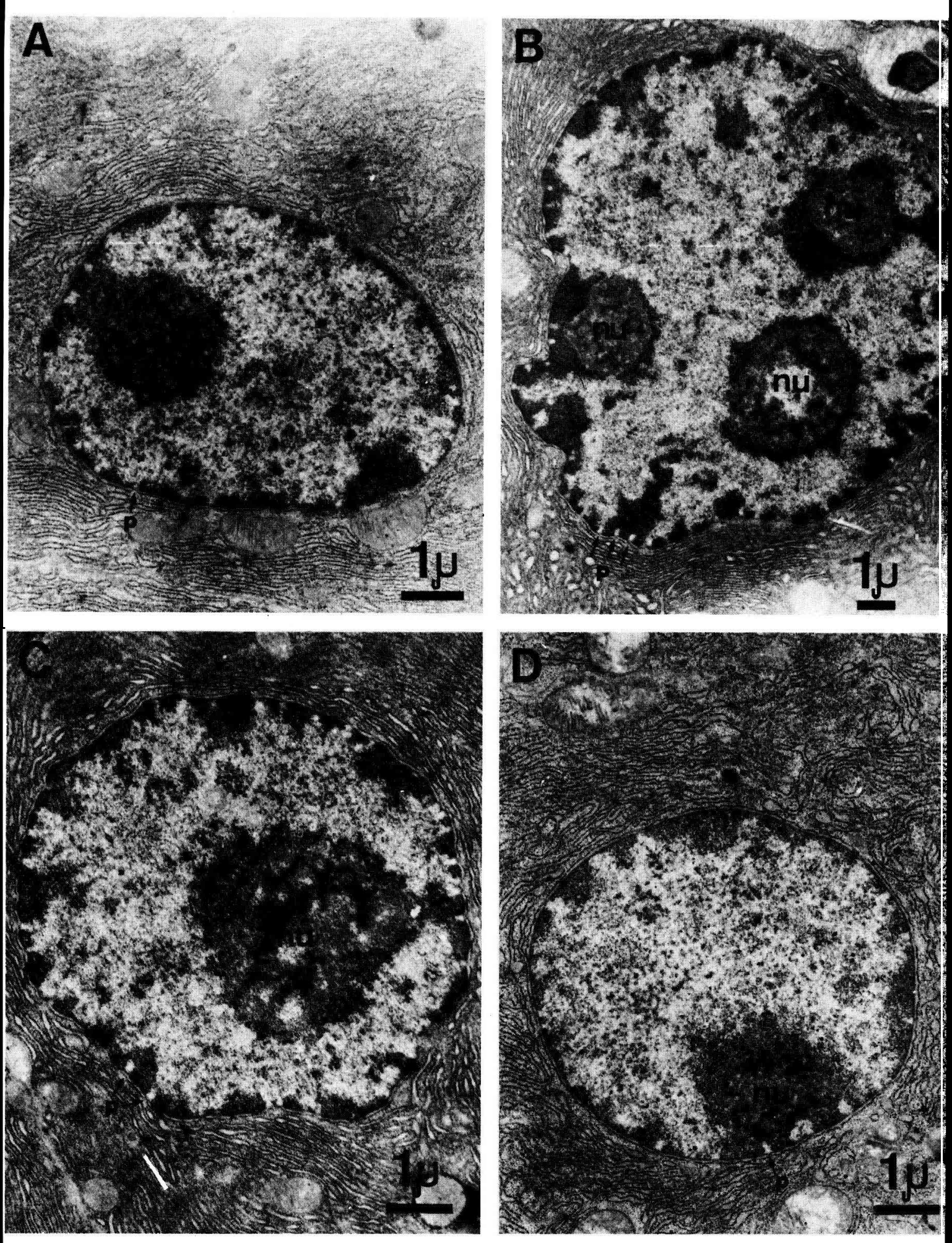
ainsi que C. Bertrand pour son aide technique et $A$. M. Remaury pour le travail de secrétariat.

\section{Références}

1. BAKER B. L., ABRAMS G. D., 1954. Effect of hypophysectomy on the cytology of the fundic gland of the stomach and on the secretion of pepsin. Am. J. Physiol., 177, 409-412.

2. BAKER B. L., CLAPP H. W., ANNABLE C. R. F., DEWEY M. M., 1961. Elevation of proteolytic activity in the pancreas of hypophysectomized rats by hormonal therapy. Proc. Soc. exp. Biol. Med., 108, 238-242.

3. JACOBSON E. D., MAGNANI T. J., 1964. Some effects of hypophysectomy on gastrointestinal functions and structure. Gut, 5, 473-479.

4. CREAN G. P., RUMSEY R. D. E., WEELER S. M., 1971. Further observation concerning the effects of hypophysectomy on gastric mucosa of the rat. Gut, 12, 721-726.

5. BAKER B. L., CLARK R. H., 1961. Influence of hypophysectomy on oxidative enzymes and size and parietal cells in gastric mucosa. Proc. Soc. exp. Biol. Med., 106, 65-67.

6. ENOCHS M. R., JOHNSON L. R., 1977. Hormonal regulation of the growth of gastrointestinal tract, biochemical and physiological aspect, 3-28. In G. B. JERZY GLASS, Progress in gastroenterology, vol. III. Grune \& Stratton.

7. MAYSTON P. D., BARROWMAN J. A., 1973. Influence of chronic administration of pentagastrin on the pancreas un hypophysectomized rats. Gastroenterology, 64, 391-399.

8. LEBLOND C. P., CARRIERE R., 1955. The effect of growth hormone and thyroxine on the mitotic rate of the intestinal mucosa of the rat. Endocrinology, 56, 261-266.

9. SESSO A., VALERI V., 1958. Nucleic acid patterns in the pancreas of hypophysectomized rats after administration of growth hormone and of thyroxine. Exp. Cell Res., 14, 201-203.

10. CREAN G. P., 1963. The endocrine system and the stomach. Vitamins Hormones, 21, 215-280.

11. ENOCHS M. R., JOHNSON L. R., 1976. Effect of hypophysectomy and growth hormone on serum and antral gastrin levels in the rat. Gastroenterology, 70, 727-732.

12. SANDER L. D., ENOCHS M. R., JOHNSON L. R., 1978. Effects of ACTH and the adrenals on serum and antral gastrin levels in the rat. Proc. Soc. exp. Biol. Med., 158, 609-613.

13. GULLO L., COSTA P. L., FONTANA G., TESSARI R., SERRA D., LABO G., 1977. Effect of adrenocorticotropic hormone on pure exocrine pancreatic secretion in man. Gastroenterology, 73, 762-764.

14. CREAN G. P., RUMSEY R. D. E., 1971. Hyperplasia of the gastric mucosa during pregnancy and lactation in the rat. J. Physiol., 215, 181-197.

15. GRUMBACH M. M., KAPLAN S. L., SCIARRA J. J., BURR I. M., 1968. Chorionic growth hormone prolactin (CGP) : secretion, disposition, biologic activity in man, and postulated function as the "growth hormone" of the second half of pregnancy. Ann. N. Y. Acad. Sci., 148, 501-531.

16. ROSENBERG V., DRELING D. A., 1977. The effect of prolactin on canine pancreatic secretion. Implications of the pathogenesis of the pancreatitis of pregnancy. Am. J. Gastroenterol., 67, 354-361.

17. BAKER B. L., BRIDGEMAN R. M., 1954. The histology of the gastrointestinal mucosa (rat) after adrenalectomy or administration of adrenocortical hormones. Am. J. Anai., 94, 363397.

FIG. 5. - Variations morphologiques observées sur les noyaux des cellules acineuses pancréatiques chez la Souris après imprégnation chronique par la gastrine (B), la CCK-PZ (C), la somatostatine (D) par rapport d̀ des onimaux n'ayant reçu que du sérum physiologique (A). Le nombre des pores nucléaires (P) est très significativement augmenté sous gastrine et $C C K$, diminué après somatostatine. Les noyaux sont hypertrophiés sous CCK-PZ mais surtout sous gastrine. De même les nucléoles (nu) sont hypertrophiés sous CCK et gastrine. Un phénomène inverse est observé sous somatostatine. Noter également les variations de répartition de l'hétérochromatine. 
18. BALAS D., 1972. Rôle des glandes surrénales sur la sécrétion des cellules de Paneth du jéjunum de hamster. C. R. Soc. Biol., 166, 420-425.

19. BALAS D., MIROUZE P., BROUSSY J., 1972. Rôle des glandes surrénales sur la sécrétion des cellules de Paneth du jéjunum de Hamster. Ełude ultrastructurale. C. R. Soc. Biol., 166, 15431554.

20. TUTTON P. J. M., 1973. Proliferation of epithelial cells in the jejunal erypts of adrenalectomized and adrenocortical hormone treated rats. Virchows Arch. Abt. B. Zellpath., 13, 227-232.

21. MOOG F., 1979. The differentiation and redifferentiation of the intestinal epithelium and its brush border membrane, 31-50. In Development of mammalian Absorptive processes. Ciba Found. Ser. 70, Elsevier North Holland Publ.

22. LEVIN R. J., 1969. The effects of hormones on the absorptive, metabolic and digestive functions of the small intestine. J. Endocr., 45, 315-348.

23. DELANEY J. P., MICHEL H., BONSACK M. E., EISENBERG M. M., 1979. Adrenal corticosteroids cause gastrin cell hyperplasia. Gastroenterology, 76, 913-916.

24. WATTS R. W., WHELDRAKE J. F., 1976. Aldosterone induced changes in RNA synthesis in rat intestine. J. Steroid Biochem., 7, 263-266.

25. CARRIERE R. M., 1967. The influence of thyroid and testicular hormones on the epithelium of crypts of Lieberkühn in the rats intestine. Anaf. Rec., 155, 423-432.

26. EARTLY H., LEBLOND C. P., 1954. Identification of the effects of thyroxine mediated by the hypophysis. Endocrinology, 54, 249-271.

27. SEINO Y., MATSUKURA S., MIYAMOTO Y., GOTO Y., TAMINATO T., IMURA H., $1976 . \quad$ Hypergastrinemia in hyperthyroidism. Clin. Endocr. Metab., 43, 852-855.

28. WRIGHT N. A., MORLEY A. R., 1971. Effect of testosterone on the growth fraction of the mouse small intestine. J. Endocrin., 50, 351-352.

29. MAYSTON P. D., BARROWMAN J. A., 1971. The influence of chronic administration of pentagastrin on the rat pancreas. Q. J. exp. Physiol., 56, 113-122.

30. TOMKINS G. M., GELEHRTER T. D., 1972. The present status of genetic regulation by hormones, 1-20. In G. LITWACK. Biochemical actions of hormones, vol. II, New York Press.

31. JOHNSON L. R., CHANDLER A. M., 1973. RNA and DNA of gastric and duodenal mucosa in antrectomized and gastrin treated rats. Am. J. Physiol., 224, 937-940.

32. JOHNSON L. R., GUTHRIE P. D., 1974. Mucosal DNA synthesis : a short term index of the trophic action of gastrin. Gastroenterology, 67, 453-459.

33. JOHNSON L. R., GUTHRIE P. D., 1974. Gastrin, secrefin, methiamide and histamine on mucosal DNA synthesis. Gastroenterology, 66, 164-718.

34. HANSEN O. H., PEDERSEN T., LARSEN J. K., REHFELD J. F., 1976. Effect of gastrin on gastric mucosal cell proliferation in man. Gut, 17, 536-541.

35. JOHNSON L. R., 1976. The trophic action of gastrointestinal hormones. Gastroenterology, 70 , 278-288.

36. JOHNSON L. R., 1977. New aspects of the trophic action of gastrointestinal hormones. Gastroenterology, 72, 788-792.

37. ENOCHS M. R., JOHNSON L. R., 1977. Changes in protein and nucleic acid synthesis in rat gastric mucosa after pentagastrin. Am. J. Physiol., 232, E223-228.

38. CASTELEYM P. P., DUBRASQUET M., WILLEMS G., 1977. Opposite effects of gastrin on cell proliferation in the antrum and other parts of the upper gastrointestinal tract in the rat. Dig. Dis., 22, 798-804.

39. DEMBINSKI A. B., JOHNSON L. R., 1979. Growth of pancreas and gastro-intestinal mucosa in antrectomized and gastrin treated rats. Endocrinology, 105, 769-773.

40. REBER H. A., JOHNSON F., DEVENEY K., MONTGOMERY C., WAY L. W., 1977. Trophic effect of gastrin on the exocrine pancreas in rats. J. surg. Res., 22, 554-560.

41. PETERSEN H., SOLOMON T., GROSSMAN L. 1., 1978. Effect of chronic pentagastrin, cholecystokinin, and secretin on pancreas of rat. Am. J. Physiol., 234, E286-293.

42. STANLEY M. D., COALSON R. E., GROSSMAN R. I., 1972 . Influence of secretin and pentagastrin on acid secretion and parietal cell number in rats. Gastroenterology, 63, 264-269.

43. WILLEMS G., VAN STEENKISTE Y., LIMBOSCH J. M., 1972. Stmulating effect of pentagastrin on cell proliferation kinetic in canine fundic mucosa. Gastroenterology, 62, 385-389.

44. WILLEMS G., LEHY T., 1975. Radioautographic and quantitative studies on parietal and peptic 
cell kinetic in the mouse. A selective effect of gastrin on parietal cell proliferation. Gastroenterology, 69, 416-426.

45. MAINZ D. L., BLACK O., WEBSTER P. D., 1973. Hormonal control of pancreatic growth. J. clin. Invest., 52, 2300-2304.

46. BARROWMMAN J. A., MAYSTON P. D., 1974. The frophic influence of cholecystokinin on the rat pancreas. J. Physiol., 238, 73P-75P.

47. FOLSCH U. R., WINCKLER K., WORMSLEY K. G., 1978. Influence of repeated administration of cholecystokinin and secretin on the pancreas of the rat. Scand. J. Gastroent., 13, 663-671.

48. SOLOMON T. E., PETERSEN H., ELASHOFF J., GROSSMAN M. I., 1978. Interaction of caerulein and secretin on pancreactic size and composition in rat. Am. J. Physiol., 235, E714-719.

49. JOHNSON L. R., GUTHRIE P. D., 1976. Effect of cholecystokinin and 16,16 dimethyl PGE on RNA and DNA of gastric and duodenal mucosa. Gastroenterology, 70, 59-65.

50. IHSE I., ARNESJO B., LUNDQVIST I., 1976. Effects on exocrine and endocrine rat pancreas of long term administration of CCK-PZ (cholecystokinin-pancreozymin) or synthetic octapeptide - CCK-PZ. Scand. J. Gastroent., 11, 529-535.

51. MORISSET J., BRANTS F., RAJOTTE D., 1977. Involvement of pancreozymin (CCK-PZ) in the control of pancreatic acinar cell growth. Gostroenterology, 72, A9/819.

52. SENEGAS F., 1980. Contribution à l'étude des facteurs de régulation d̀ long ef moyen termes du pancréas exocrine, de l'intestin grêle et de l'estomac. Th. Ełat Sci. no 958 , Toulouse.

53. JOHNSON L. R., GUTHRIE P. D., 1974. Secretin inhibition of gastrin stimulated deoxyribonucleic acid synthesis. Gastroenterology, 67, 601-606.

54. WISEMAN D. A., JOHNSON L. R., 1976. Evidence that secretin does not have direct antitrophic effects on the rat stomach. Proc. Soc. exp. Biol. Med., 153, 277-279.

55. LEHY T., DUBRASQUET M., BONFILS S., 1979. Effect of somatostatin on normal and gastricstimulated cell proliferation in the gastrin and intestinal mucosal of the rat. Digestion, 19, 99-109.

56. GLEESON M. H., BLOOM S. R., POLAK R. M., HENRY K., DOWLING R. H., 1971. Endocrine fumor in kidney affecting small bowel structure motility and absorptive function. Gut, 12, 773-782.

57. BUCHAN A. M. J., POLAK J. M., 1980. The classification of the human gastroenteropancreatic endocrine cells. Investigative and cell pathology, vol. 3, Gut Endocr., 51-72.

58. WILLAMSON R. C. N., BUCHHOLTZ T. W., MALT R. A., 1978. Humoral stimulation of cell proliferation in small bowel after transection and resection in rats. Gastroenterology, 75 , 249-254.

59. WESER E., 1978. Role of gastrin in intestinal adaptation after small bowel resection. Gastroenterology, $75,323$.

60. BALAS D., SENEGAS-BALAS F., BERTRAND C., FREXINOS J., RIBET A., 1980. Effects of pancreatic duct ligation on the hamster intestinal mucosa. Histological findings. Digestion, 20, 157-167.

61. SENEGAS-BALAS F., BALAS D., BOUISSON M., RIBET A., 1981. Effect of pancreatic duct ligation on the hamster intestinal mucosa. Variation of several hydrolases. Digestion, 21, 83-91.

62. CHENG H., LEBLOND C. P., 1974. Origin, differentiation and renewal of the four main epithelial cell types in the mouse small intestine. V. Unitarian theory of the origin of the four epithelial cell types. Am. J. Anat., 141, 537-561.

63. ALPERS D. H., TEDESCO F. J., 1975. The possible role of pancreatic protease in the turn over of intestinal brush border proteins. Biochim. biophys. Acta, 401, 28-40.

64. ALPERS D. H., 1977. Protein turn over in intestinal mucosal villus and crypt brush border membranes. Bioch. Biophys. Res. Commun., 75, 130-135.

65. SIMOES-NUNES C., CORRING T., CHAYVIALLE J. A., 1980. Mecanisme du phénomène de rétroaction négative de la sécrétion pancréatique chez le porc : résultats préliminaires. Journ. Digestion-Absorption, 20-21 nov. 1980, Toulouse.

66. ESTIVAL A., FAGOT P., CLEMENTE F., RIBET A., 1980. Action des enzymes pancréatiques ou de leurs inhibiteurs sur les niveaux enzymatiques du pancréas ef de l'intestin chez le rat. Journ. Digestion-Absorption, 20-21 nov. 1980, Toulouse.

67. SASSIER P., BERGERON M., 1978. Specific inhibition of cell proliferation in the mouse intestine by an aqueous extract of rabbit colon. Cell Tissue Kinet., 11, 641-650. 
68. LAVAL J., PRADAYROL L., BALAS D., CLEMENTE F., RIBET A., 1978. The quantitative distribution of certain enzymes along the small intestine of the rat and its correlation with the villous area and the Paneth cells. Digestion, 17, 309-316.

69. STEINER M., BOUGES H. R., FREEDMAN L. S., 1968. Effect of starvation on the tissue composition of the small intestine in the rat. Am. J. Physiol., 215, 75-77.

70. MCNEIL L. K., HAMILTON J. R., 1971. The effect of fasting on disaccharidase activity in the rat small infestine. Pediatrics, 47, 65-72.

71. ALTMAN G. G., 1972. Influence of starvation and refeeding on mucosal size and epithelial renewal in the rat small intestine. Am. J. Anat., 133, 391-400.

72. LICHTENBERGER L., WELSH J. D., JOHNSON L. R., 1975. Relationships between the changes in gastrin levels and intestinal properties in the starved rat. Am. J. Dig. Dis., 21, 33-38.

73. JOHNSON L. R., COPELAND E. M., DUDRICK S. J., LICHTENBERGER L. M., CASTRO G. A., 1975. Structural and hormonal alterations in the gastrointestinal tract of parenterally fed rats. Gastroenterology, 68, 1177-1183.

74. SENEGAS-BALAS F., BALAS D., SUSINI C., BERTRAND C., RIBET A., 1980. Effet de la pénicillamine sur la muqueuse de l'intestin grêle du rat. Etude histophysiologique. Gastroenterol. clin. biol., 4, 26-36.

75. FOLSCH U. R., CREUZTFELD M. D., 1977. Pancreatic duct cells in rats : secretory studies in response to secretin, cholecystokinin-pancreozymin and gastrin in vivo. Gastroenterology, 73, 1053-1059.

76. FRIEDMAN M., 1977. Chemical basis for pharmacogical and therapeutic action of penicillamine, Adv. exp. Med. Biol., 86B, 649-673.

77. MERALDI J. P., HRUBY V. J., BREWSTERA I. R., 1977. Relative conformational rigidity in oxytocin and (1 penicillamine) oxytocin : a proposal for the relationship of conformational flexibility to peptide hormone agonism and antagonisme. Proc. nat. Acad. Sci. U. S. A., 74, 1373-1377.

78. BRYANT M. G., BLOOM S. R., 1979. Distribution of the gut hormones in the primate intestinal tract. Gut, 20, 653-659.

79. BALAS D., SENEGAS F., FREXINOS J. PRADAYROL L., BROUSSY J., RIBET A., 1974. Action des hormones digestives sur la muqueuse jéjuno-iléale chez la Souris et le Hamster. Etude histophysiologique. Biol. Gastrol., 7, 187-199.

80. SENEGAS-BALAS F., BALAS D., PRADAYROL L., LAVAL J., RIBET A., 1979. Comparative effects of CCK-PZ on certain intestinal hydrolases in the mucosa and in the luminal content of the Hamster jéjuno-ileum. Acta hepato-gastroenterol., 26, 486-492.

81. "Cross linking ". In Adv. exp. Med. Biol., 86B, 1977.

82. MELROSE A. G., RUSSELL R. I., DICK A., 1964. Gastric mucosal structure and function after vagotomy. Gut, 5, 546-549.

83. GREAN G. P., GUNN A. A., RUMSEY R. D. E., 1969. The effect of vagotomy on the gastric mucosa of the rat. Scand. J. Gastroenterol., 4, 645-680.

84. WILLEMS G., 1977. Factors controlling cell proliferation in gastroduodenal mucosa, 29-51. In G. B. Jerzy Glass. Progress in Gastroenterology. Vol. III, Grune \& Stratton.

85. McGUIGAN J. E., TRUDEAU W. L., 1972. Serum gastrin levels before and after vagotomy and pyloroplasty or vagotomy and antrectomy. New-Engl. J. Med., 286, 184-188.

86. JAFFE B. M., CLENDINNEN B. G., CLARKE R. J., 1974. Effect of selective and proximal vagotomy on serum gastrin. Gastroenterology, 66, 944-953.

87. DELINCE P., WILLEMS G., DE GRAEF J., 1978. Antral gastrin cell proliferation after vagotomy in rats. Digestion, 18, 27-34.

88. LEHY T., VOILLEMOT N., DUBRASQUET M., DUFOUGERAY. E, 1975. Gastrin cell hyperplasia in rats with chronic antral stimulation. Gastroenterology, 68, 71-82.

89. WILLEMS G., GEPTS W., BREMER A., 1977. Endogenous hypergastrinemia and cell proliferation in the fundic mucosa in dogs. Dig. Dis., 22, 419-423.

90. BOMMELAER G., GUT P. H., 1979. Protection by histamine receptor antagonists and prostaglandin against gastric mucosal barrier disruption in the rat. Gastroenterology, 77, 303-308.

91. FEDELI G., ANTI M., RAPACCINI G. L., DE VITIS I., BUTTI A., CIVELLO, I. M., 1979. A controlled study comparing cimetidine treatment to an intensive antacid regimen in the therapy of uncomplicated duodenal ulcer. Dig. Dis. Sci., 24, 758-762. 
92. HANSKY J., STERN A. I., KORMAN M. G., WANGH J., 1979. Effect of long term cimetidine on serum gastrin in duodenal ulcer. Dig. Dis. Sci., 24, 468-470.

93. KORMAN M. G., HANSKY J., WAUGH J., 1979. The effect of cimetidine on gastrin release in ulcer disease. Aust. N. Z. J. Med., 9, 367-369.

94. WALLIN L., MADSEN T., BRANDSBORG M., BRANDSBORG O., LARSEN N. E., 1979. The influence of cimetidine on basal gastro-oesophageal sphincter pressure, intragastric $\mathrm{pH}$, and serum gastrin concentration in normal subjects. Scand. J. Gastroenterol., 14, 349-359.

95. PETERSEN H., SOLOMON T., GROSSMAN M. I., 1979. Pancreatic secretion in rat after chronic treatment with secretin plus caerulein. Gostroenterology, 76, 790-794.

96. SUNDLER F., HAKANSON R., LOREN I., LUNDQVIST I., 1980. Amine storage and function in peptide hormone producing cells. Investigative and cell pathology, vol 3, Gut Endocr., 87-104.

97. POLAK J. M., BLOOM S. R., 1979. Neuro peptides and the antrum, 15-30. In REHFELD J. H., Gastrin and the vagus, Acad. Press.

98. UVNAS-WALLENSTEN K. P., 1977. Occurrence of gastrin in gastric juice, in antral secretion and in antral perfusate of cats. Gastroenterology, 73, 487-491.

99. ESCOURROU J., PUDEBAT M., CHAYVIALLE J. A., FAGOT-REVURAT P., PRADAYROL L., RIBET A., 1980. Hormonal polypeptide in pure human pancreatic juice collected by E. R. C. P. Abstr., no 20, Meet. Am. Pancreatic Assoc., nov. 6-7, Chicago-lll.

100. LARSSON L. I., 1977. Ontogeny of peptide producing nerves and endocrine cells of the gastroduodeno-pancreatic region. Histochemistry, 54, 133-142.

101. LARSSON L. I., 1980. On the possible existence of multiple endocrine paracrine and neurocrine messengers in secretory cell systems. Investigative and cell pathology, vol. 3, Gut Endocr., 73-86.

102. BASTIE M. J., BALAS D., SENEGAS-BALAS F., BERTRAND C., PRADAYROL L., FREXINOS J., RIBET A., 1979. A cyto-physiological study of the G-cell secretory cycle in the antrum mucosa of the hamster and of the rat. Scand. J. Gastroent., 14, 35-48.

103. LARSSON L. I., 1978. ACTH-like immunoreactivity in the gastrin cell. Independent changes in gastrin and ACTH-like immunoreactivity during ontogeny. Histochemistry, 56, 245-251.

104. LARSSON L. I., 1978. Gastrin and ACTH-like immunoreactivity occurs in two ultrastructurally distinct cell types of rat antropylore mucosa. Hisfochemistry, 58, 33-48.

105. GRUBE D., WEBER E., 1980. Immunoreactivities of gastrin (G) cells. I Dilution dependent staining of $G$ cells by antisera and non-immune sera. Histochemistry, 65, 223-238.

106. GRUBE D., 1980. Immunoreactivities of gastrin (G) cells. II Non specific binding of immunoglobulins to G-cells by ionic interactions. Histochemistry, 66, 149-167.

107. ITOH S., HIROTA R., KATSUURA G., ODAGUCHI K., 1979. Suppressive effect of pentagasirin on pituitary adrenocortical secretion. Endocr. jap., 26, 741-744.

108. REHFELD J. F., LARSSON L. I., 1980 . Neural regulation of pancreatic hormone secretion by C-terminal tetrapeptide of CCK. Nature, 284, 33-38.

109. FOURMY D., PRADAYROL L., VAYSSE N., RIBET A., 1980. Effet du tetrapeptide "CCK-4 » sur la sécrétion pancréatique exocrine du Rat in vivo et in vitro. Journées Digestion-Absorption, 20-21 nov. 1980, Toulouse. Reprod. Nutr. Dévelop., 21, 806.

110. GOLTERMANN N., MAJUMBAR A. P., 1979. Stimulation of gastric mucosal protein synthesis by different molecular form of gastrin. Horm. Res., 11, 142-150.

111. MAJUMDAR A. R., GOLTERMANN N., 1979. Chronic administration of pentagastrin. Effects on pancreatic and nucleic-acid contents and protein synthesis in rat. Digestion, 19, 144-147.

112. GARDNER J. D., 1979. Regulation of pancreatic exocrine function in vitro : initial steps in the action of secretagogues. Ann. Rev. Physiol., 41, 55-66.

113. MAINZ D. L., BLACH O., WEBSTER P. D., 1973. Hormonal control of pancreatic growth. J. clin. Invest., 52, 2300-2304. 